\title{
Self Efficacy and Self Care Behaviour among Patients with Type 2 Diabetes Mellitus - A Cross Sectional Survey
}

\author{
Manjula GB ${ }^{1}$, Dr. Jayarani Premkumar ${ }^{2}$ \\ ${ }^{1}$ Diabetes Educator, Samastha Hospitals, Bangalore, Karnataka, India \\ ${ }^{2}$ Former Nursing Superintendent, Christian Medical College, Vellore, Tamilnadu
}

\begin{abstract}
A Cross sectional survey was conducted to assess self efficacy and self care behavior of patients with type 2 diabetes mellitus and its relationship with socio demographic and morbidity related variables in a sample of 150 patients randomly selected using random number table. Setting was the out- patient diabetic clinic of a tertiary care hospital in Trivandrum, Kerala. Self efficacy was measured by Diabetes Self Efficacy Scale developed by researcher and self care behaviour was assessed by Summary of Diabetes Self Care Activities (Revised version) developed by DJ. Toobert et al. 2000. After obtaining ethical clearance from the institution review board, data was collected from out-patients attending a diabetic clinic of a tertiary hospital in Kerala. Subjects were selected randomly using random number table. An informed written consent was obtained. Data was collected by interview method using standardised tools whose validity and reliability was ensured. Descriptive statistics was used to describe the characteristics of subjects. Frequency and percentage was used to describe level of self efficacy and self care behaviour. The relationship between self efficacy with self care behaviour and HbAlc was assessed using Spearman's Rank Correlation Chi-square test was used to find out the association of socio-demographic and morbidity variables with self efficacy self care behaviour and HbAlc values. Majority of subjects had average self efficacy and self care behaviour in domains of diet, exercise, blood sugar monitoring, medication and insulin administration and foot care. Mean HbAlc value was $8.87 \pm 0.79$. A positive correlation was noted between self efficacy and self care behaviour (p<0.001). Also increase in self efficacy and self care behaviour was associated with a decrease in HbAlc values $(p<0.001)$.It was noted that HbAlc and self efficacy was significantly associated with age $(p<0.05)$. Duration of disease did affect HbAlc $(p<0.05)$, self efficacy $(p<0.001)$ and self care behaviour significantly $(p<0.01)$. Type of treatment affected significantly HbAlc values $(p<0.001)$ and self efficacy $(p<0.05)$. Family history of diabetes significantly affected HbA1c $(p<0.001)$, self efficacy $(p<0.01)$ and self care behaviour $(p<0.05)$. HbAlc values are significantly associated with presence of complications $(p<0.01)$. Only a very small percentage of study subjects had good self efficacy and self care behaviour. It is noteworthy that the mean HbAlc values were much higher than the ADA recommended levels. Study revealed that an increase in self efficacy brings about an increase in self care behaviour. Also a decrease in HbAlc values is noted with an increase in self efficacy and self care behaviour.
\end{abstract}

Keywords: Self efficacy, Self care behavior, Glycemic control, Type 2 Diabetes Mellitus .

\section{Introduction}

Around the world, more people are living in large towns and cities, are living longer lives, taking less exercise and eating less healthy types of food in larger quantities than they ever did before. The result is that the total number of people in the world with diabetes is spiraling out of control. A national survey of diabetes conducted in six major cities in India in the year 2000 has shown that the prevalence of diabetes in urban Indian adults was $12.1 \%{ }^{1}$.

In India, there is a great burden due to micro and macrovascular complications of diabetes. This is because the status of diabetes control in India is far from ideal. Based on the available data, the mean glycated hemoglobin levels are around $9 \%$ which is at least $2 \%$ higher than the goal currently suggested by international bodies ${ }^{2}$.A behavior change is required on part of patient by understanding that diabetes care is their personal responsibility.

Making their own decisions for improving blood sugar levels and performing related self chosen actions and maintaining its long term performance is the key element in diabetes self care management. A belief in one's ability to perform the task of self care management that will lead to the desired outcome of attaining glycemic control is regarded as self- efficacy in diabetes. The extent of strong feelings that patient experiences about the situation related to diabetes determines how sustaining the behavior change will be. How far patients' confidence in managing disease by themselves materializes to self care behavior needs to be studied.

\section{Statement of Problem}

A study to assess self efficacy and self care behaviour among patients with type 2 diabetes mellitus in a selected hospital in Trivandrum, Kerala.

\section{Objectives}

1) To assess the level of self efficacy and self care behaviour among patients with type 2 diabetes mellitus.

2) To find out the relationship between self efficacy, self care behaviour and $\mathrm{HbAlc}$ values.

3) To associate selected socio-demographic and morbidity variables with self efficacy, self care behaviour and HbAlc values among patients with type 2 diabetes mellitus. 
International Journal of Science and Research (IJSR)

ISSN (Online): 2319-7064

Index Copernicus Value (2013): 6.14 | Impact Factor (2013): 4.438

\section{Material and Methods}

A Cross sectional survey was carried out in the out- patient diabetic clinic of a tertiary care hospital inTrivandrum, Kerala. A sample of 150 patients with type 2 diabetes mellitus was randomly selected. Self efficacy was measured by Diabetes Self Efficacy Scale developed by researcher and self care behaviour was assessed by Summary of Diabetes Self Care Activities (Revised version) developed by DJ. Toobert et al. 2000.

After obtaining ethical clearance from the institution review board, data was collected from out-patients attending a diabetic clinic of a tertiary hospital in Kerala. Subjects were selected randomly using random number table. An informed written consent was obtained. Data was collected by interview method using standardised tools whose validity and reliability was ensured. HbAlc values was measured by HPLC method using Biorad. Data collected was analysed using descriptive and inferential statistics. Descriptive statistics was used to describe the characteristics of subjects. Frequency and percentage was used to describe level of self efficacy and self care behaviour. The relationship between self efficacy with self care behaviour and $\mathrm{HbAlc}$ was assessed using Spearman's Rank Correlation. Chi-square test was used to find out the association of socio-demographic and morbidity variables with self efficacy self care behaviour and $\mathrm{HbA} 1 \mathrm{c}$ values.

\section{Results}

Table 1: Distribution of subjects according to their sociodemographic variables

\begin{tabular}{|c|c|c|}
\hline Demographic & \multicolumn{2}{|c|}{$\begin{array}{l}\text { Frequency } \\
\text { Percentage }\end{array}$} \\
\hline Variables & $f$ & $\%$ \\
\hline \multicolumn{3}{|l|}{ Age in years } \\
\hline 1. $31-40$ & 1 & 0.6 \\
\hline $41-50$ & 35 & 23.3 \\
\hline 3. $51-60$ & 61 & 40.67 \\
\hline $61-70$ & 53 & 35.30 \\
\hline \multicolumn{3}{|l|}{ Sex } \\
\hline 1. $\quad$ Male & 80 & 53.33 \\
\hline 2. $\quad$ Female & 70 & 46.67 \\
\hline \multicolumn{3}{|l|}{ Religion } \\
\hline 1. Hindu & 94 & 62.67 \\
\hline 2. $\quad$ Christian & 36 & 24 \\
\hline 3. $\quad$ Muslim & 20 & 13.33 \\
\hline \multicolumn{3}{|l|}{ Place of residence } \\
\hline 1. Urban & 111 & 74 \\
\hline 2. $\quad$ Rural & 39 & 26 \\
\hline \multicolumn{3}{|l|}{ Marital status } \\
\hline 1. $\quad$ Married & 124 & 82.67 \\
\hline 2. $\quad$ Separated/ Divorcee/ & 26 & 17.33 \\
\hline \multicolumn{3}{|l|}{ Widow } \\
\hline \multicolumn{3}{|l|}{ Education } \\
\hline 1. $\quad$ Graduate or post graduate & 26 & 17.33 \\
\hline 2. Intermediate or post high school diploma & 55 & 36.67 \\
\hline 3. $\quad$ High school & 41 & 27.33 \\
\hline 4. $\quad$ Middle school & 19 & 12.67 \\
\hline 5. Primary school & 9 & 6 \\
\hline \multicolumn{3}{|l|}{ Occupation } \\
\hline 1. Semiprofession & 11 & 7.33 \\
\hline
\end{tabular}

\begin{tabular}{|ll|c|c|} 
2. $\quad$ Clerical,shop-owner,farmer & 14 & 9.33 \\
\hline $3 . \quad$ Skilled worker & 24 & 16 \\
\hline $4 . \quad$ Semi-skilled worker & 14 & 9.33 \\
\hline $5 . \quad$ Unskilled worker & 2 & 1.33 \\
\hline $6 . \quad$ Unemployed & 85 & 56.67 \\
\hline Income & & \\
\hline $1 . \quad 17900-35799$ & 26 & 17.33 \\
\hline $2 . \quad 13420-17899$ & 55 & 36.67 \\
\hline $3 . \quad 8950-13419$ & 40 & 26.67 \\
\hline $4 . \quad 5360-8949$ & 18 & 12 \\
\hline $5 . \quad 1791-5359$ & 11 & 7.33 \\
\hline Socioeconomic status & & \\
\hline $1 . \quad$ Lower middle & 26 & 17.33 \\
\hline $2 . \quad$ Middle & 43 & 28.67 \\
\hline $3 . \quad$ Upper middle & 81 & 54 \\
\hline Source of income & & \\
\hline $1 . \quad$ Self & 38112 & 25.34 \\
\hline $2 . \quad$ Spouse/Children & & 74.66 \\
\hline Lives with & & \\
\hline $1 . \quad$ Spouse & 54 & 36 \\
\hline $2 . \quad$ Spouse and children & 70 & 46.7 \\
\hline $3 . \quad$ Children & 22 & 14.7 \\
\hline $4 . \quad$ With other family members & 4 & 2.7 \\
\hline Habits of only male subjects & & \\
\hline $1 . \quad$ Alcoholism & 21 & 26.25 \\
\hline $2 . \quad$ Smoking & 7 & 8.75 \\
\hline $3 . \quad$ Both alcoholism and smoking & 24 & 30 \\
\hline $4 . \quad$ None & 28 & 35 \\
\hline Total & $\mathbf{8 0}$ & $\mathbf{1 0 0}$ \\
\hline
\end{tabular}

Table 1 shows that majority of subjects are in the age group of 51-60 (40.67\%) Majority are males (53.33\%) and are Hindus (62.67\%). 74\% subjects are mostly residing in urban areas. Majority of them are married $(82.67 \%)$.With regard to the educational status, majority $(36.67 \%)$ hold an intermediate or post high school diploma. However, majority of them $(56.67 \%)$ are unemployed. Regarding income, majority $(36.67 \%)$ earn between $13420-17899$ per month. Majority (54\%) belonged to upper middle class. Majority of them lived with spouse and children $(46.7 \%)$ who also contributed major chunk of family income (74.66 \%). Regarding the habits, none of the females had the habit of smoking or alcoholism. Hence describing habits among only males, it was found that majority of them did not have any habits. However, $30 \%$ had the habit of both drinking alcohol and smoking and $26.25 \%$ of them had the habit of drinking alcohol. 


\section{International Journal of Science and Research (IJSR) \\ ISSN (Online): 2319-7064 \\ Index Copernicus Value (2013): 6.14 | Impact Factor (2013): 4.438}

Table 2: Distribution of subjects according to their morbidity variables

\begin{tabular}{|c|c|c|}
\hline \multirow{2}{*}{\begin{tabular}{|l|} 
Morbidity \\
Variables \\
\end{tabular}} & \multicolumn{2}{|c|}{$(n=150)$} \\
\hline & f & $\%$ \\
\hline \multicolumn{3}{|l|}{ Duration of diabetes(yrs) } \\
\hline $1 . \leq 5$ & 37 & 24.67 \\
\hline 2. $6-10$ & 65 & 43.33 \\
\hline $3.11-15$ & 26 & 17.33 \\
\hline $4.16-20$ & 19 & 12.67 \\
\hline $5.21-25$ & 3 & 2 \\
\hline $6 .>25$ & 0 & 0 \\
\hline \multicolumn{3}{|l|}{ System of treatment followed } \\
\hline 1. Allopathy & 124 & 82.67 \\
\hline 2. Allopathy and homeopathy & 17 & 11.33 \\
\hline 3. Allopathy and ayurveda & 9 & 6 \\
\hline \multicolumn{3}{|l|}{ Type of treatment } \\
\hline 1. Oral anti diabetic agents & 115 & 76.7 \\
\hline 2. Oral anti diabetic agents and insulin & 35 & 23.3 \\
\hline \multicolumn{3}{|l|}{ Starting of oral anti diabetic agents } \\
\hline 1. Soon after diagnosis & 139 & 92.67 \\
\hline 2. 1-3 years after diagnosis & 11 & 7.33 \\
\hline \multicolumn{3}{|c|}{ Adherence to medications for the past one year } \\
\hline 1. Regular & 104 & 69.33 \\
\hline 2. Irregular & 46 & 30.67 \\
\hline \multicolumn{3}{|l|}{ Self monitoring of GRBS using glucometer } \\
\hline 1. Yes & 45 & 30 \\
\hline 2. No & 105 & 70 \\
\hline \multicolumn{3}{|l|}{ Family history of diabetes } \\
\hline 1. Yes & 124 & 82.67 \\
\hline $2 . \mathrm{No}$ & 26 & 17.33 \\
\hline \multicolumn{3}{|l|}{ Diabetics in the family } \\
\hline 1. Father or Mother & 73 & 48.67 \\
\hline 2. Both parents & 22 & 14.67 \\
\hline 3. Siblings/uncle/aunt & 46 & 30.67 \\
\hline 4. Father or Mother and siblings/uncle/aunt & 6 & 4 \\
\hline 5. Both parents and siblings/uncle/aunt & 3 & 2 \\
\hline
\end{tabular}

\begin{tabular}{|l|c|c|}
\hline Diabetic complications & 38 & 25.33 \\
\hline 1. Neuropathy & 18 & 12 \\
\hline 2. Coronary artery disease & 94 & 62.7 \\
\hline 3. None & \multicolumn{3}{|l|}{} \\
\hline Co-morbidities & 17 & 11.33 \\
\hline 1. Hypertension & 8 & 5.33 \\
\hline 2. Dyslipidemia & 67 & 44.67 \\
\hline 3. Both & 58 & 38.67 \\
\hline 4. None & &
\end{tabular}

Table 2 shows that majority of the subjects $(43.33 \%)$ are diabetics since past 6-10 years. $82.67 \%$ are following allopathic system of medicines only. Majority of them are treated with only oral anti diabetic agents (76.7\%).Majority of subjects $(92.67 \%)$ were put on oral anti diabetic agents soon after diagnosis. With regard to medication adherence, $69.33 \%$ of them were adherent. Usage of glucometer for self monitoring of blood sugars was not a practice in majority of subjects $(70 \%)$ Family history of diabetes was noticed in $82.62 \%$ of subjects. Either father or mother was a diabetic in $48.67 \%$ of subjects. Neuropathy was the diabetic complication reported in majority of subjects $(25.33 \%)$. Majority of subjects $(44.67 \%)$ had both hypertension and dyslipidemia as co-morbidities.

Table 3: Distribution of mean blood sugar values

\begin{tabular}{|ll|c|c|}
\hline \multirow{2}{*}{ Laboratory measures } & \multicolumn{2}{|c|}{$(\mathbf{n = 1 5 0})$} \\
\cline { 3 - 4 } & Mean & SD \\
\hline 1. & HbA1c & 8.87 & 0.79 \\
\hline 2. & FBS & 162.68 & 21.56 \\
\hline 3. & PPBS & 205.46 & 30.61 \\
\hline
\end{tabular}

Table 3 shows that the Mean HbA1c was $8.87 \pm 0.79$, Mean FBS was $162.68 \pm 21.56$ and Mean PPBS was $205.46 \pm$ 30.61 .

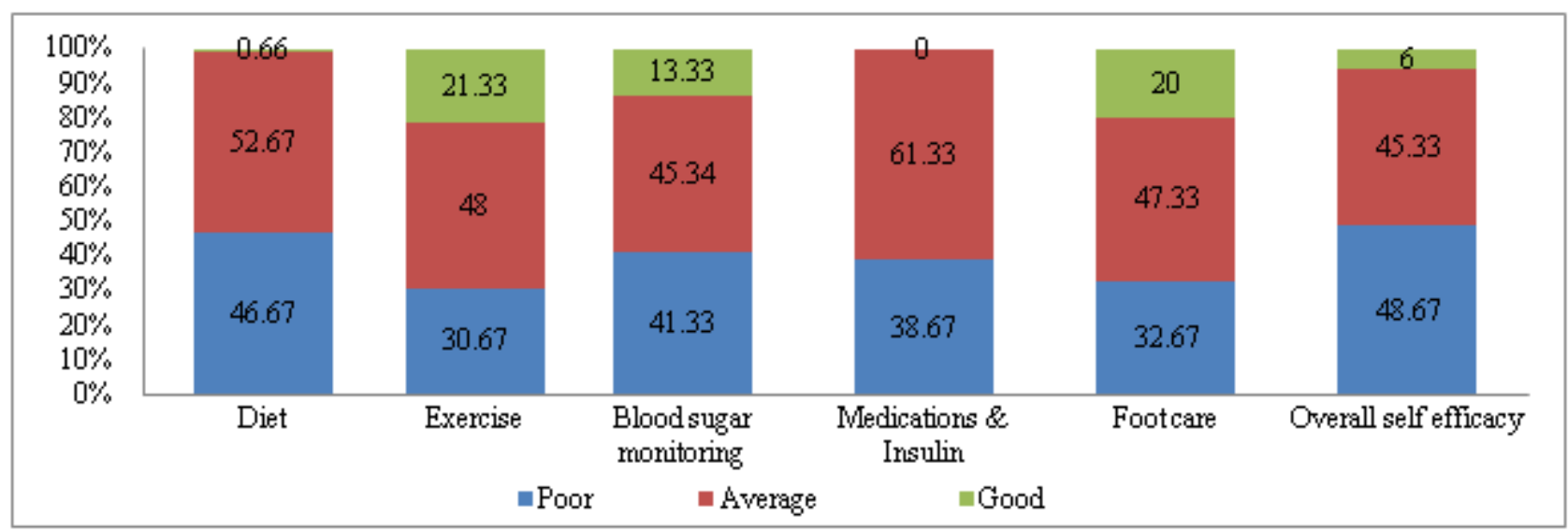

Chart 1: Domain wise description of level of self efficacy among subjects

The above chart reveals that majority of subjects had average self efficacy in diet (52.67\%). 46.67\% had average self efficacy. Good self efficacy was found in $0.66 \%$. Self efficacy in exercise was average (48\%) for majority of subjects. It was poor in $30.67 \%$. Good self efficacy was noted among $21.33 \%$ With regard to self efficacy in blood sugar monitoring, majority (45.34\%) had average self efficacy. Poor self efficacy was noted among $41.33 \%$. Good self efficacy was seen in $13.33 \%$. Data on self efficacy in medication and insulin administration revealed that $61.33 \%$ had average self efficacy and $38.67 \%$ had poor self efficacy. None had good self efficacy. Regarding foot care, $47.33 \%$ had average self efficacy. Poor self efficacy was found in $32.67 \%$. Only $20 \%$ had good self efficacy in foot care. Overall self efficacy was poor in majority (48.67\%). 45.33\% had average self efficacy. Only $6 \%$ had good overall self efficacy. 


\section{International Journal of Science and Research (IJSR) \\ ISSN (Online): 2319-7064}

Index Copernicus Value (2013): 6.14 | Impact Factor (2013): 4.438

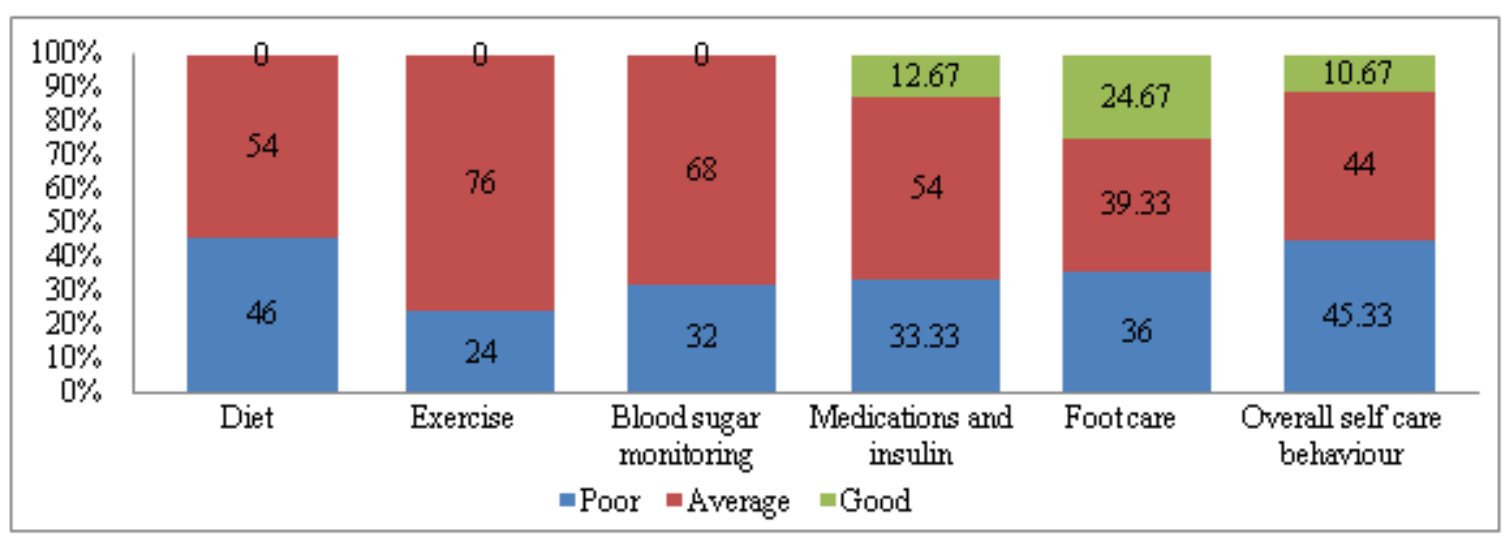

Chart 2: Domain wise description of level of self care behaviour among subjects.

It is evident from the above chart that majority of subjects had average self care behaviour in diet (54\%).Poor self care behaviour was found in $46 \%$. None had good self care behavior for diet. Self care behaviour for exercise was average $(76 \%)$ for majority of subjects. Poor self care behaviour was noted among $24 \%$. None had good self care behavior for exercise. With regard to self care behaviour in blood sugar monitoring, majority $(68 \%)$ had average self care behaviour. Poor self care behaviour was noted among $32 \%$. None had good self care behavior for blood sugar monitoring. Data on self care behaviour in medication and insulin administration revealed that $54 \%$ had average self care behaviour. Poor self care behavior was noted in 33.33\% Good self care behavior was found in $12.67 \%$. Self care behavior on foot care was average in $39.33 \%$.Poor self care behavior was exhibited among $36 \%$. Only $24.67 \%$ had good self care behaviour in foot care. Overall self care behaviour was poor in majority (45.33\%). It was average in $44 \%$.Only $10.67 \%$ had good overall self care behaviour.

Table 4: Correlation between self efficacy, self care behaviour and $\mathrm{HbAlc}$ values

\begin{tabular}{|c|c|c|}
\hline Correlation between variables & $\begin{array}{c}\text { Spearman's Rank } \\
\text { Correlation Co-efficient }\end{array}$ & $\mathrm{p}$ value \\
\hline $\begin{array}{c}\text { Self efficacy and Self care } \\
\text { behaviour }\end{array}$ & 0.881 & 0.0001 \\
\hline Self care behavior and HbA1c & -0.568 & 0.0001 \\
\hline Self efficacy and HbA1c & -0.68 & 0.0001 \\
\hline
\end{tabular}

The above table elicits a significant positive correlation between self efficacy, self care behaviour and $\mathrm{HbA} 1 \mathrm{c}$ values. An increase in self efficacy brings about an increase in self care behaviour. Also a decrease in $\mathrm{HbAlc}$ values is noted with an increase in self efficacy and self care behaviour.

Association of self efficacy, self care behaviour and HbA1c values with socio demographic and morbidity variables

It was noted that $\mathrm{HbA1c}$ and self efficacy was significantly associated with age $(\mathrm{p}<0.05)$ but not with self care behaviour. Gender, socio economic status and with whom subject lives was not associated with the variables of study. Duration of disease did affect HbAlc $(\mathrm{p}<0.05)$, self efficacy $(p<0.001)$ and self care behaviour significantly $(p<0.01)$. Type of treatment affected significantly $\mathrm{HbAlc}$ values $(p<0.001)$ and self efficacy $(p<0.05)$. Self care behaviour was not affected. Family history of diabetes significantly affected HbAlc $(p<0.001)$, self efficacy $(p<0.01)$ and self care behaviour $(\mathrm{p}<0.05)$. Presence of complications is not significantly associated with self efficacy and self care behaviour. HbA1c values are significantly associated with presence of complications $(\mathrm{p}<0.01)$. Associated comorbidities did not affect the variables significantly.

\section{Discussion}

Study revealed that self efficacy and self care behavior was average in majority on domains of diet, exercise, blood sugar monitoring, medication and insulin administration and foot care. Only $6 \%$ had good overall self efficacy and $10.67 \%$ had good overall self care behaviour. Similar findings were reported by a study conducted in South India which found that $59 \%$ of patients did not follow their diabetic diet, $63 \%$ did not practice adequate exercise. Only $31 \%$ had good foot care habits and $61 \%$ had good medication adherence. ${ }^{3}$ Another study noted that low self efficacy in each of recommended diabetes behaviours is related to decreased adherence of the specific behavior. ${ }^{4}$ The study showed a positive correlation between self efficacy and self care behavior. This finding was consistent with a similar study conducted in Malaysia. ${ }^{5}$ Also an increase in self efficacy is associated with a decrease in HbAlc values. Similar results were obtained in several other studies ${ }^{6,7}$

It was noted that age, duration of disease, type of treatment, family history and presence of complications significantly affected $\mathrm{HbAlc}$ values and self efficacy. Self care behavior was affected by duration of disease and family history of diabetes. Several other studies have concluded the same ${ }^{8,9}$

\section{Recommendations}

1) Health professionals must develop competency to address the psychosocial factors affecting diabetes self care management.

2) Design behavioural intervention programmes for diabetic patients that incorporates strategies to develop self efficacy.

3) Individually tailored interventions must be the focus of practice followed by case management enabling adherence to the behavioural change

\section{Volume 4 Issue 12, December 2015}




\section{Conclusion}

Only a very small percentage of study subjects had good self efficacy and self care behaviour. It is noteworthy that the mean $\mathrm{HbAlc}$ values were much higher than the ADA recommended levels. Study revealed that an increase in self efficacy brings about an increase in self care behaviour. Also a decrease in HbAlc values is noted with an increase in self efficacy and self care behaviour.

\section{References}

[1] Ramachandran A, Snehalatha C, Kapur A, et al. High prevalence of diabetes and impaired glucose tolerance in India. National Urban Diabetes Survey. Diabetologia 2001; 44 : 1094-101.

[2] Zaman FA, Pal R, Zaman GS. et al. Glucose indices, frank and undetected diabetes in relation to hypertension and anthropometry in a south Indian rural population. Indian Journal of Public Health 2011; 55:34-7.

[3] Sasi TS, Kodali M, Burra CK, Muppala SB et al. Self care activities, diabetic distress and other factors which affected the glycemic control in a tertiary care teaching hospital in South India. Journal of Clinical and Diagnostic Research [serial online] 201305 [cited: 2013 May 21] 5857-860 Available from http://www.jcdr.net//back_issues.asp

[4] Mishalia M, Omera $\mathrm{H}^{-}$,A D Heymannb DA. The importance of measuring self-efficacy in patients with diabetes. Family Practice (2011) 28 (1): 82-87.

[5] Sharoni AS, and Wu VS, Self-efficacy and self-care behavior of Malaysian patients with type 2 diabetes: a cross sectional survey.Nursing and Health Sciences (2012), 14, 38-45

[6] Wynn Nyunt S, Howteerakul N, Suwannapong N, Rajatanun T. Self-efficacy, self-care behaviors and glycemic control among type- 2 diabetes patients attending two private clinics in Yangon, Myanmar. Southeast Asian J Trop Med Public Health. 2010 Jul;41(4):943-51.

[7] Osborn YC, Cavanaugh K, Wallston AK, Rothman LR, Self-Efficacy Links Health Literacy and Numeracy to Glycemic Control. Journal of Health Communication: International Perspectives. Volume 15, Supplement 2, 2010 146-158

[8] Sakchai Kaehaban, Prathurng Hongsranagon and Piyalamporn Havanond. Factors influencing self-care behaviors of diabetic patients in diabetes mellitus clinic, Changhan hospital, Roi et Province, Thailand. J Health Res 2010, 24(suppl 1): 21-26

[9] Amente T, Belachew T, Hailu E, Berhanu N, Self care practice and its predictors among adults with diabetes mellitus on follow up at Nekemte hospital diabetic clinic, West Ethiopia. World Journal of Medicine and Medical Science [Internet] March 2014[cited 2014 May4] Vol. 2, No. 3. Available from http://www.wjmms.com 